Research Article

\title{
Mechanical Properties of Sandstones under Initial Unloading Damage
}

\author{
Hengbin Zhang, Lehua Wang ${ }^{D}$, Jianlin Li, Huafeng Deng, and Xiaoliang Xu \\ Key Laboratory of Geological Hazards on Three Gorges Reservoir Area, Ministry of Education, China Three Gorges University, \\ Yichang 443002, China \\ Correspondence should be addressed to Lehua Wang; lehuatg@126.com
}

Received 14 December 2020; Revised 25 February 2021; Accepted 13 April 2021; Published 30 April 2021

Academic Editor: Xingzhou Chen

Copyright (c) 2021 Hengbin Zhang et al. This is an open access article distributed under the Creative Commons Attribution License, which permits unrestricted use, distribution, and reproduction in any medium, provided the original work is properly cited.

\begin{abstract}
To study the influence of initial unloading damage on the mechanical properties of sandstone, the repeated loading test of unloading damaged sandstone was carried out considering 8 initial unloading quantities of $100 \%, 93.33 \%, 86.67 \%, 80 \%, 73.33 \%$, $66.67 \%, 40 \%$, and $0 \%$. The results were compared with those of the triaxial compression test of intact samples. The results show that the peak strength of intact samples is higher than that of unloading damaged samples, and the difference is more obvious when the unloading quantity is more than $80 \%$. During the unloading process, the strain increasing rate of rock samples is obvious, and the lateral dilatation is significant, and the deformation modulus and compressive strength of the rock sample deteriorate obviously. From the energy point of view, the greater the unloading damage, the smaller the stored elastic strain energy, which leads to the decrease of peak strength. At present, the unloading fracture inside the rock sample has developed, and the failure mode of the sample gradually changes from compression shear failure to tensile shear failure. In the process of engineering rock mass excavation, the unloading area and unloading damage amount of the rock mass is a dynamic adjustment process. To ensure the safety of the engineering rock mass, it is suggested to determine reasonable reinforcement time, reinforcement area, and reinforcement measures.
\end{abstract}

\section{Introduction}

The geological environment of the rock mass is usually complex. Under the influence of various human factors and geological tectonic movement, the stress state of the rock mass is also changing constantly. The simple loading and unloading tests usually carried out in the test cannot reflect the stress state of the rock mass well. In recent years, with the development of the society, human demand for resources has grown, and large-scale water conservancy continues to develop. In the process of dam foundation excavation, the unloading effect is usually along the excavation direction. When the dam body is completed, it will show the loading effect. In the unloading process, it will cause irreversible damage to the rock mass which has a certain impact on the subsequent loading. Therefore, it is of great significance to carry out a loading test on the rock mass with unloading damage.
In recent years, many scholars have performed a lot of research on unloading damage. Yin and Li [1], Gong et al. [2], and Liu et al. [3] studied the confining pressure unloading tests with different rates and modified the Hoek-Brown criterion formula. Qiu et al. [4] carried out unloading confining pressure tests with different initial damage degrees and proposed two new unloading mechanical description parameters: strain confining pressure increment ratio and uniform confining pressure drop. Huo et al. [5], Liu et al. [6], and Liu et al. [7] conducted unloading tests on mudstone, raw coal, and granite under different unloading paths. They analyzed the damage and deterioration effects of deformation, strength, and strength parameters during the unloading process. Li et al. [8] and Wang et al. [9] analyzed the stress-strain curve and failure characteristics and proposed the elastic brittle plastic mechanical model considering the unloading state. Apollaro 
et al. [10], Tallinn et al. [11], and Alt-Epping et al. [12] carried out a series of unloading tests. The results show that unloading causes irreversible damage to rocks, and its degradation effect has a gradual development trend with the increase of unloading quantity. Hu et al. [13], Zhong et al. [14], Ni and Xu [15], and Liu et al. [16] used FLAC and other software to analyze the influence of unloading on the strength of rock samples during coring. A new coring method is proposed to reduce the damage of rock samples in the process of sampling. Zhu et al. [17] and $\mathrm{Ma}$ et al. [18] studied rock samples with different initial damage from the perspective of dynamics. They obtained the conclusion that the greater the initial damage is, the greater the porosity of rock samples is. Based on the previous research foundation, Li et al. [19], Jiang et al. [20], and Zhao et al. [21] divided the unloading failure process into three types from the energy point of view: damage weakening stage, damage stable development stage, and damage accelerated development stage. Based on the existing isotropic damage constitutive theory and continuum damage mechanics method, Chen et al. [22], Luo et al. [23], Li et al. [24], and Wang et al. [25] established a three-dimensional isotropic damage model of rock and analyzed the variation law fitting formula of uniaxial compressive strength, Poisson's ratio, and other mechanical parameters with initial damage. Dai et al. [26] carried out triaxial loading and unloading tests under different confining pressures. Based on the changes of energy dissipation and secant modulus during deformation, two damage variables were defined. Qiu et al. [27] carried out a prepeak unloading test on marble and proposed that irreversible strain, stable damage deformation, and unstable damage deformation are used to define damage variables. Zhang et al. [28] introduced confining pressure unloading factor to describe damage evolution characteristics of mechanical properties under the unloading state. Wang et al. [29] analyzed the reinforcement measures of the damaged rock mass through test data and studied the mechanical properties of a reinforced rock mass. Yu et al. [30] studied the influence of osmotic pressure on the mechanical properties of sandstone with different bedding dip angles and established the corresponding constitutive model. Yang et al. [31] studied the reinforcement method of unloading the rock mass. At the same time, he proposed a constitutive model considering the reinforcement effect.

Many scholars have laid a good foundation for the indepth understanding of the mechanical properties of the rock mass. In practical engineering, most of the rock mass contains certain damage, and some even have been damaged close to failure, and there is little research on the mechanical properties of this part of the rock mass. Based on previous research, the loading tests of rock samples with different initial damage are carried out, and the mechanical properties of rock samples under different initial unloading damage conditions are studied. The research results have a certain reference values for excavation engineering.

\section{Samples Preparation and Test Plan}

2.1. Samples Preparation. In this paper, the typical sandstones in the Three Gorges Reservoir area are selected as the research objects. After the rock samples are taken back from the site, the drilling samples are made into standard samples with $50 \mathrm{~mm}$ diameter $\times 100 \mathrm{~mm}$ height, as shown in Figure 1. At the same time, the test is carried out on the RMT-150C rock mechanics test system, as shown in Figure 2.

2.2. Test Plan. The different damage degree is determined by the unloading quantity as follows [32]:

$$
\Delta \sigma_{3}=\left(\frac{\sigma_{3}-\sigma_{3}^{i}}{\sigma_{3}-\sigma_{d}}\right) \times 100 \%,
$$

where $\sigma_{3}$ is the initial confining pressure. We combined the local in-situ stress conditions and the test scheme in reference [32], which is taken as $20 \mathrm{MPa} ; \sigma_{d}$ is the confining pressure value at failure, $12.5 \mathrm{MPa}$ in this test; $\sigma_{3}^{i}$ is the confining pressure value when unloading to grade $i$. 12.5 MPa, 13 MPa, 13.5 MPa, 14 MPa, 15 MPa, 17 MPa, and $20 \mathrm{MPa}$ are taken in this test, and the corresponding unloading quantities are 100\%, 93.33\%, 86.67\%, 80\%, $73.33 \%, 66.67 \%, 40 \%$, and $0 \%$.

The stress path is shown in Figure 3. The initial confining pressure is $20 \mathrm{MPa}$, and $75 \%$ of the peak strength is selected as the axial stress level of the unloading point. After unloading to different unloading levels, the axial pressure is increased, and the samples are failured.

The specific test steps are as follows:

(1) In the hydrostatic loading stage, confining pressure and axial pressure are loaded to the hydrostatic pressure of $20 \mathrm{MPa}$.

(2) In the stage of axial stress loading, the method of stress control is adopted and the axial pressure is applied to the initial unloading point. In this paper, $75 \%$ of the ultimate failure strength is taken.

(3) In the unloading stage of confining pressure, when the axial pressure reaches the unloading point, the axial stress remains unchanged, and the confining pressure is gradually reduced to a predetermined value, and different initial unloading damages are applied to the rock samples.

(4) In the stage of repeated axial stress loading, the confining pressure is kept unchanged and the axial pressure is increased until the specimen destroyed.

(5) Another group of rock samples is taken for triaxial compression tests under different predetermined confining pressures until the stress-strain curve entered the stable residual stage, and then, we take out the sample. The peak strength and residual strength of the triaxial compression test are obtained, and they are compared with the test results of different initial unloading damage rock samples. 


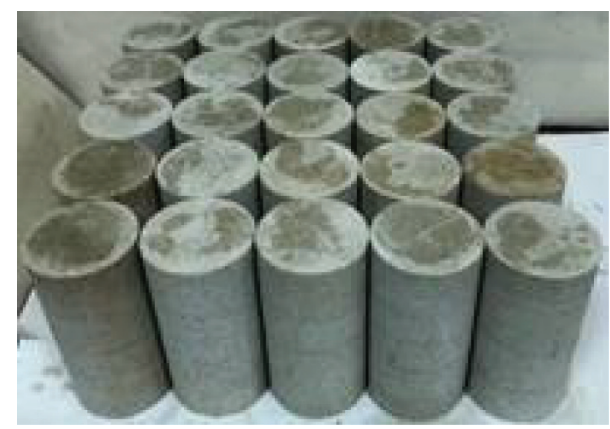

FIgUre 1: Finished specimens.

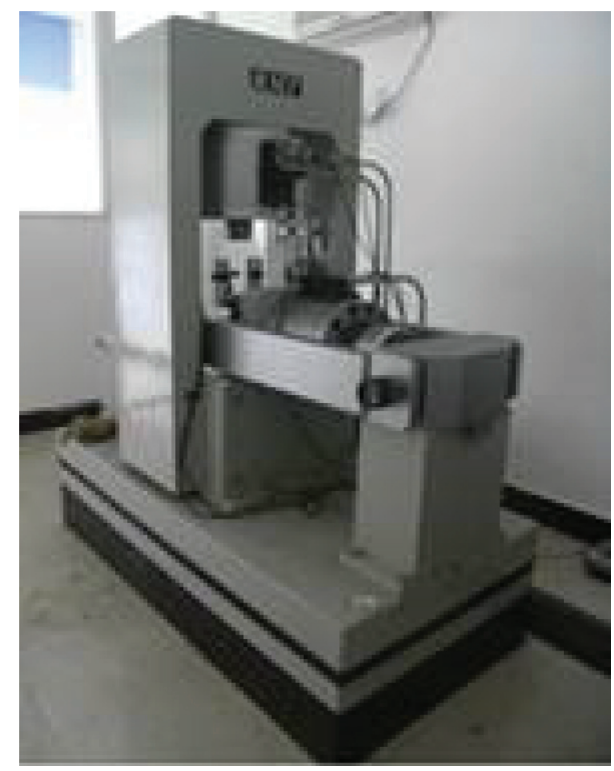

FIGURE 2: RMT-150C rock mechanics test system.

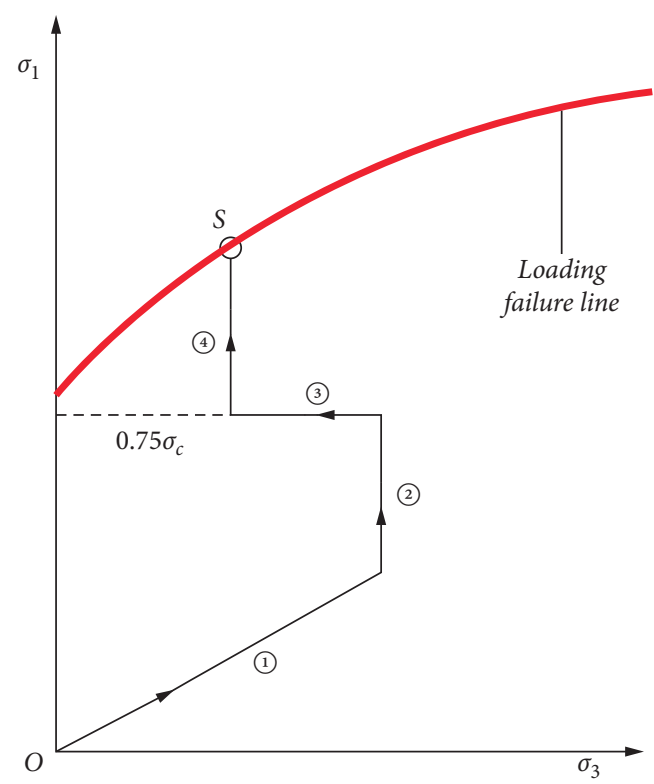

FIgURE 3: Stress path.

\section{Results and Discussion}

3.1. Characteristic Analysis of Stress-Strain Curves. The stress-strain curves of rock samples with different unloading damage are shown in Figure 4, and the stress-strain curves of the triaxial compression test under corresponding confining pressures are shown in Figure 5.

From Figures 4 and 5, it can be seen that

(1) The shape of the stress-strain curves under triaxial loading is basically the same, which can be divided into compaction stage, elastic stage, yield stage, postpeak softening stage, and residual strength stage. In the elastic stage, the slopes of stress-strain curves of different rock samples are approximately equal, and the elastic modulus of rock samples are approximately the same, which indicates that the selected samples have less dispersion. The yield stage of the samples is short, and the postpeak stress drops rapidly, thus showing the brittle characteristics of sandstones. With the confining pressure increasing, the peak strength and residual strength increase gradually.

(3) Compared with the triaxial compression test, the two groups of test curves are basically the same in the axial compression loading stage. In the confining pressure unloading stage, the axial strain of the damaged rock samples will increase to a certain extent, and the greater the unloading quantity, the greater the increment of axial strain, which reflects an arc with a low slope rate in the stress-strain curve. It is indicated that the greater the unloading quantity, the smaller the peak strength of the specimen.

\subsection{Analysis of the Strain Confining Pressure Compliance in} the Unloading Stage. To analyze the influence of unloading quantity of confining pressure on axial strain increment in the unloading process, the strain confining pressure compliance is introduced $\Delta \dot{\varepsilon}_{i}$ [33]. The concept of $\Delta \dot{\varepsilon}_{i}$ is the ratio of strain increment unloading $\left(\Delta \varepsilon_{i}\right)$ and confining pressure unloading quantity $\left(\sigma_{3}-\sigma_{3}^{i}\right)$ between the starting point and the ending point of confining pressure:

$$
\Delta \dot{\varepsilon}_{i}=\frac{\Delta \varepsilon_{i}}{\sigma_{3}-\sigma_{3}^{i}},
$$

where $\Delta \dot{\varepsilon}_{i}$ represents the strain confining pressure compliance, which is the strain increment caused by the unit confining pressure unloading quantity. The larger the value of the strain confining pressure compliance, the more obvious the influence of unloading on the axial strain.

We take the axial strain increment and confining pressure unloading quantity corresponding to the starting and ending points of the unloading stage, and we calculate the axial strain confining pressure compliance under different unloading quantity according to equation (2) and draw the relationship between axial strain confining pressure 

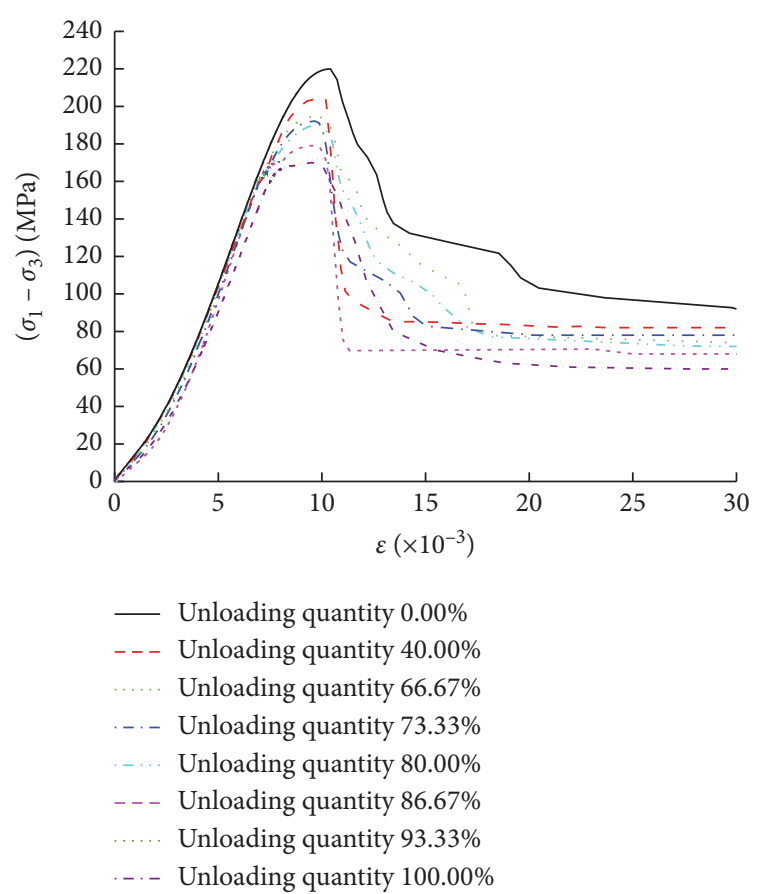

Figure 4: Stress-strain curves of rock samples with different unloading damage under triaxial compression.

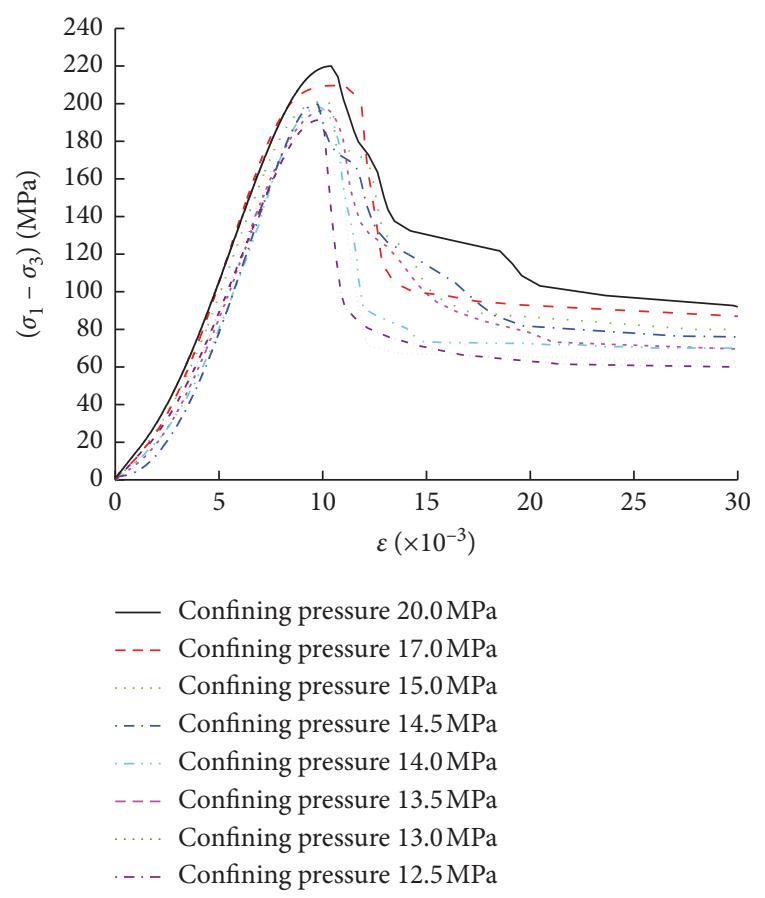

FIgURE 5: Stress-strain curves of the conventional triaxial compression test.

compliance and unloading quantity, as shown in Figure 6 and Table 1.

It can be seen from Figure 6 and Table 1 that

(1) The influence of unloading quantity on the axial strain confining pressure compliance of the rock

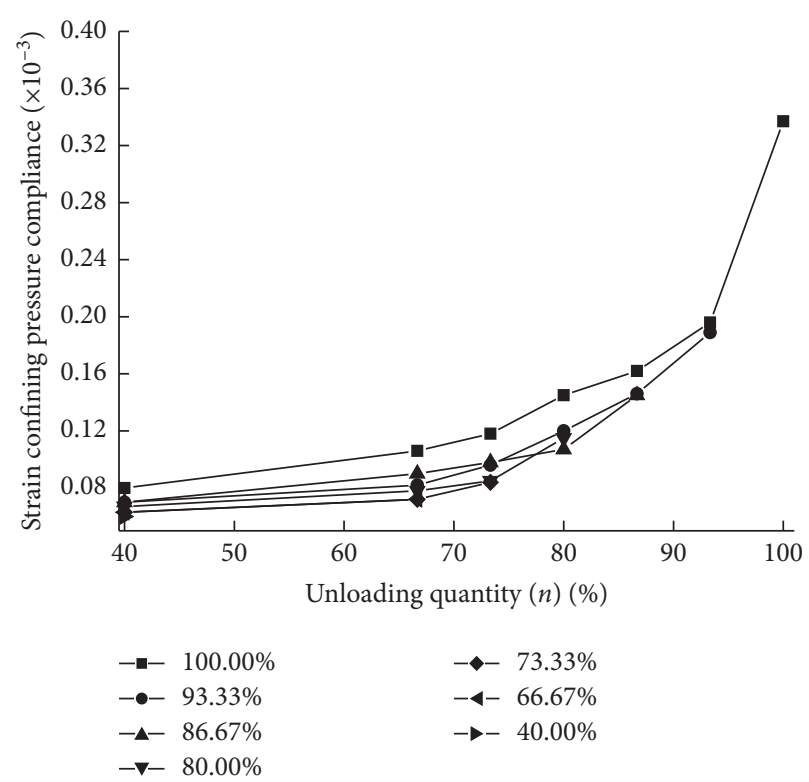

FIGURE 6: The curves of axial strain confining pressure compliance and unloading quantity in the unloading stage.

sample is significant. With the increase of unloading quantity, the axial strain confining pressure compliance increases gradually. When the unloading quantity is less than $80 \%$, the increase of axial strain confining pressure compliances is slow. When the unloading quantity is more than $80 \%$, the axial strain confining pressure compliances increase rapidly, which is a nonlinear mutation stage.

(2) When the unloading quantity increases from $40 \%$ to $100 \%$, the average values of the axial strain confining pressure compliance of the samples are $0.068 \times 10^{-3}$, $0.083 \times 10^{-3}, 0.096 \times 10^{-3}, 0.122 \times 10^{-3}, 0.151 \times 10^{-3}$, $0.192 \times 10^{-3}$, and $0.337 \times 10^{-3}$ under different unloading conditions. When the unloading quantity increases from $0 \%$ to $80 \%$, the axial strain confining pressure compliances change slowly with an average increment of $0.054 \times 10^{-3}$. When the unloading quantity increases from $80 \%$ to $100 \%$, the axial strain confining pressure compliances show a nonlinear mutation stage with an increment of $0.215 \times 10^{-3}$. When the unloading quantity is higher than $80 \%$, the axial strain confining pressure compliance corresponding to the failure point becomes larger obviously.

\subsection{Strength Parameter Analysis}

3.3.1. Peak Strength Analysis. In the repeated loading stage, it can also be seen that the unloading damage caused by different unloading quantities is different. The relationship between deviatoric stress and confining pressure in the triaxial test of rock samples with different initial damage is counted, and Figure 7 is drawn.

It can be seen from Figure 7 that 
TABLE 1: Compliance statistics of strain confining pressure.

\begin{tabular}{lcccccccc}
\hline \multirow{2}{*}{ Confining pressure (MPa) } & \multicolumn{3}{c}{ Unloading capacity } & & \\
& 0.00 & $40.00 \%$ & $66.67 \%$ & $73.33 \%$ & $80.00 \%$ & $86.67 \%$ & $93.33 \%$ & $100.00 \%$ \\
\hline 12.5 & 100.00 & 0.080 & 0.106 & 0.118 & 0.145 & 0.162 & 0.196 \\
13.0 & 93.33 & 0.070 & 0.082 & 0.096 & 0.120 & 0.146 & 0.189 \\
13.5 & 86.67 & 0.067 & 0.078 & 0.091 & 0.117 & 0.142 & - & - \\
14.0 & 80.00 & 0.067 & 0.078 & 0.085 & 0.115 & - & - \\
14.5 & 73.33 & 0.063 & 0.072 & 0.084 & - & - & - \\
15.0 & 66.67 & 0.063 & 0.072 & - & - & - & - \\
17.0 & 40.00 & 0.060 & - & - & - & - & - \\
20.0 & 0.00 & - & - & - & - & - & - \\
\hline
\end{tabular}

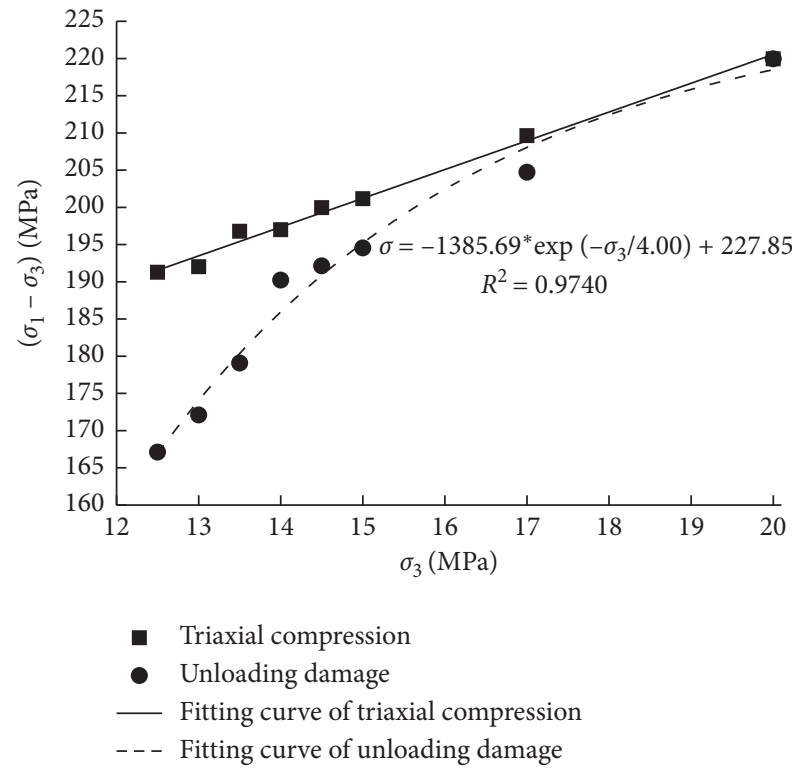

Figure 7: The curves of peak strength and confining pressure.

(1) Under different confining pressures, the peak strength of conventional triaxial compression test rock samples is linear fitting, while the curve of peak strength of rock samples with different unloading damage and confining pressure is approximately an arc curve. When the unloading quantity is 0 , the peak strength is $219.96 \mathrm{MPa}$ (without unloading damage). And, the smaller the unloading quantity (the smaller the unloading damage degree), the better the coincidence of the two curves, which indicates that the unloading damage has little influence on the peak strength of the rock sample. The greater the unloading quantity (the greater the unloading damage degree), the greater the difference between the two curves, which indicates that the influence of the unloading damage degree on the peak strength of the rock sample is more obvious.

(2) When the unloading quantity increases from $40 \%$ to $100 \%$, the peak strength of the unloading damaged rock sample decreases from $204.72 \mathrm{MPa}$ to 167.12 MPa and that of the conventional triaxial compression specimen corresponding to confining pressure decreases from 209.62 $\mathrm{MPa}$ to $191.28 \mathrm{MPa}$, corresponding to a decrease of $2.34 \%$ to $12.63 \%$. Compared with the two groups of data, when the unloading quantity is less than $80 \%$, the difference in peak strength is small. When the unloading quantity is higher than $80 \%$, the peak strength of unloading damaged rock samples decreases sharply, and the difference of peak strength between the two groups of rock samples increases obviously.

3.3.2. Degradation Factor of Unloading Damage Analysis. Compared with the intact rock sample, the peak strength of the unloading damaged rock sample is lower than that of the conventional triaxial compression test under the same confining pressure, and the peak strength is decreased, resulting in a certain damage deterioration effect. To analyze the damaging effect of peak strength, the unloading damage deterioration factor $D_{i}$ is defined as follows:

$$
D_{i}=\frac{\sigma_{S i}-\sigma_{X i}}{\sigma_{S i}},
$$

where $\sigma_{X i}$ is the peak strength of the unloading damaged rock sample and $\sigma_{S i}$ is the peak strength of the triaxial compression test rock sample under the same confining pressure. The larger the degradation factor of unloading damage is, the greater the damaging effect is.

At the same time, the unloading damage deterioration factor is set as a function of the unloading quantity. According to the data in Figure 7, the unloading damage deterioration factor is fitted with the unloading quantity, as shown in Figure 8.

It can be seen from Figure 8 that, with the increase of unloading quantity, the unloading damage deterioration factor increases gradually, and the minimum value is 0 when the unloading quantity is $0 \%$, and the maximum value is 1 when the unloading quantity is $100 \%$. The unloading damage deterioration factor and confining pressure showed an exponential growth trend. When the unloading quantity is less than $80 \%(D<0.4)$, the change of the unloading damage deterioration factor is relatively gentle. When the unloading quantity increases from $80 \%$ to $100 \%(D \geq 0.4)$, the unloading damage deterioration factor shows a rapid growth trend.

3.4. Deformation Modulus in Unloading Stage and Repeated Loading Stage Analysis. The deformation modulus of rock samples in the unloading stage is counted and plotted as Figure 9 and Table 2. 


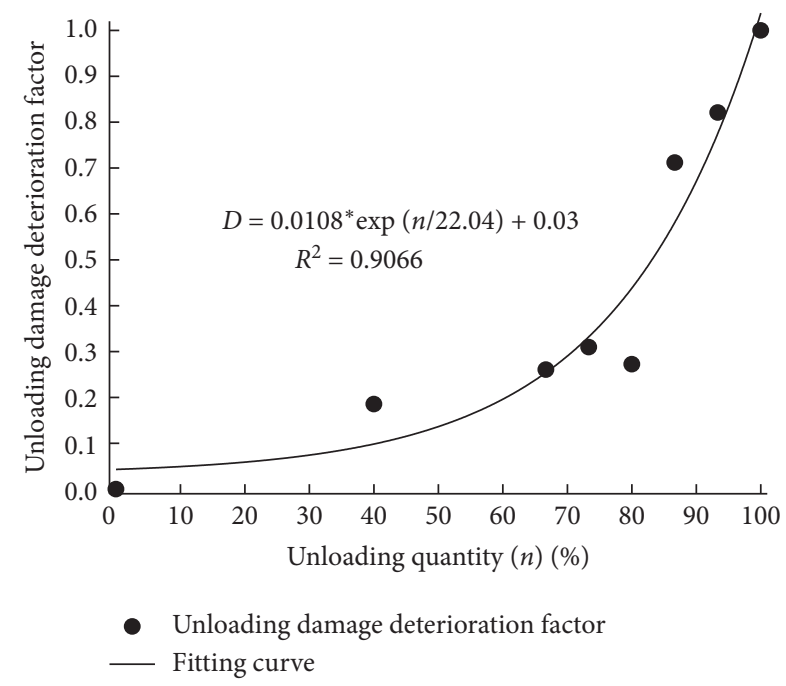

FIGURE 8: The curve of the unloading damage deterioration factor and unloading quantity.

Figure 9 and Table 2 show that the deformation modulus of the rock sample is about $23 \mathrm{GPa}$ before unloading, which indicates that the selected sample has small dispersion. In the unloading process, with the increase of unloading quantity, the deformation modulus of the sample decreases gradually, which shows a trend of slowing first and then steeping. When the unloading quantity is $40 \%, 66.67 \%$, and $73.33 \%$, the reduction range of the deformation modulus is $1.00 \%$, $2.13 \%$, and $3.22 \%$ and the average change range of the deformation modulus is $2.12 \%$. When the unloading quantity is $80 \%, 86.67 \%, 93.33 \%$, and $100 \%$, the deformation modulus of the sample decreases suddenly during the unloading process. With the increase of the unloading quantity, the deformation modulus of the sample decreases sharply. The range of reduction is $5.69 \%, 9.05 \%, 12.24 \%$, and $22.17 \%$, with an average value of $12.29 \%$. It means that, in the unloading stage, with the increase of unloading quantity, the declining trend of the deformation modulus is more obvious.

\subsection{Axial Strain Energy Density in Unloading and Repeated Loading Stages' Analysis}

3.5.1. Principle of Energy Calculation. Considering the deformation of a rock mass element under the action of external force, it is assumed that there is no heat exchange between the specimen and the outside in the whole test process. The work done by the external force is the total input energy, which is defined as $U$ [34] according to the principle of energy conservation:

$$
U=U^{d}+U^{e}
$$

where $U^{d}$ is the energy consumption of rock and $U^{e}$ is the elastic strain energy released by rock.

Figure 10 shows the stress-strain curve of rock. $E$ represents the elastic modulus of rock. The damage and deformation of rock are caused by the energy consumption $U^{d}$ of rock. The dissipation of energy is an irreversible process, but the release and absorption of energy are reversible as long as certain conditions are met.

Therefore, the total energy absorbed by the rock mass can be expressed as follows [34]:

$$
U=\int_{0}^{\varepsilon_{1}} \sigma_{1} \mathrm{~d} \varepsilon_{1},
$$

where $\sigma_{1}$ is the axial principal stress and $\varepsilon_{1}$ is the axial strain.

3.5.2. Influence of Unloading on Axial Strain Energy Density. Equation (5) is used to calculate the work done by the testing machine on the unit volume of the rock sample. We draw Figure 11. The testing machine cannot measure the lateral displacement of the specimen. Therefore, the energy density of the second loading process is calculated, which is called the axial strain energy density, as shown in Figure 12.

It can be seen from Figure 11 that

(1) With the increase of initial unloading, the axial strain energy density decreases gradually. When the initial unloading quantity is less than $80 \%$, the axial strain energy density decreases linearly. When the initial unloading quantity is greater than $80 \%$, the axial strain energy density of the unloading damaged rock sample decreases sharply and the curve presents a nonlinear mutation stage, which indicates that the axial strain energy density has a great loss at this time.

(2) When the initial unloading quantity is $0 \%$, the axial strain energy density of the specimen is $120.45 \mathrm{~kJ} \cdot \mathrm{m}^{-3}$. When the initial unloading quantity is less than $80 \%$, the energy density changes by $88.23 \mathrm{~kJ} \cdot \mathrm{m}^{-3}$. When the initial unloading quantity is more than $80 \%$, the energy density decreases by $35.65 \mathrm{~kJ} \cdot \mathrm{m}^{-3}$.

(3) The reason is that when the initial unloading quantity is less than $80 \%(D<0.4)$, the cracks in the rock sample are not fully developed, the unloading damage is small, and the rock can still store high energy. Therefore, the work done by the testing machine on the rock sample is stored in the form of elastic potential energy. When the initial unloading quantity is greater than $80 \%(D \geq 0.4)$, the cracks in the rock are more frequent. At this time, the elastic potential energy stored in the rock is sharply reduced and the rock sample is destroyed only with little work done by the testing machine.

To quantitatively analyze the influence of unloading quantity on the ultimate storage energy of samples, the degree of energy damage in the unloading process and repeated loading process are defined as the deterioration degree. Among them, the difference between the energy density of samples with different unloading quantity and that of samples with $0 \%$ unloading quantity is recorded as the total deterioration degree $S_{i}$ [35]. The difference of 


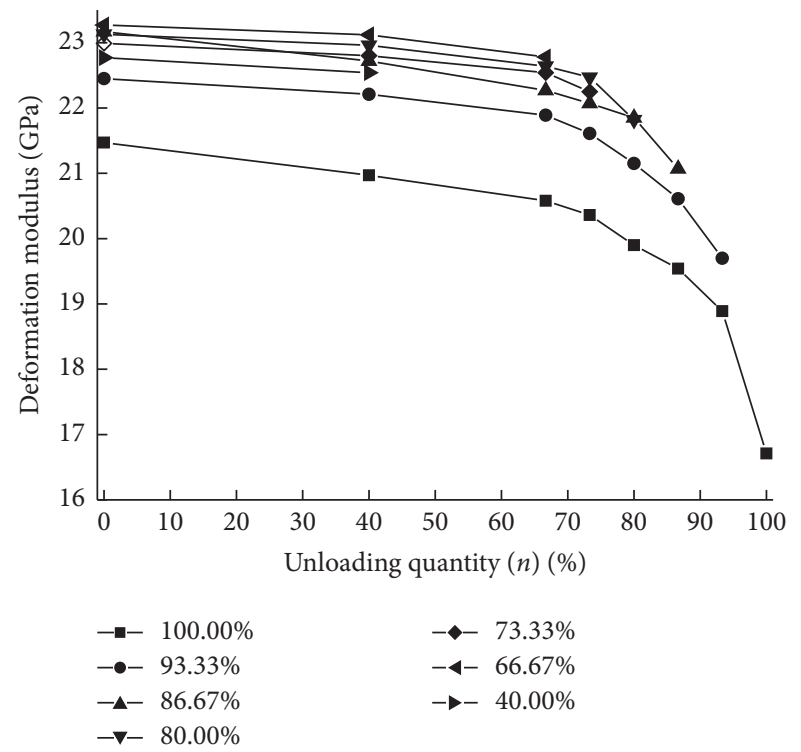

(a)

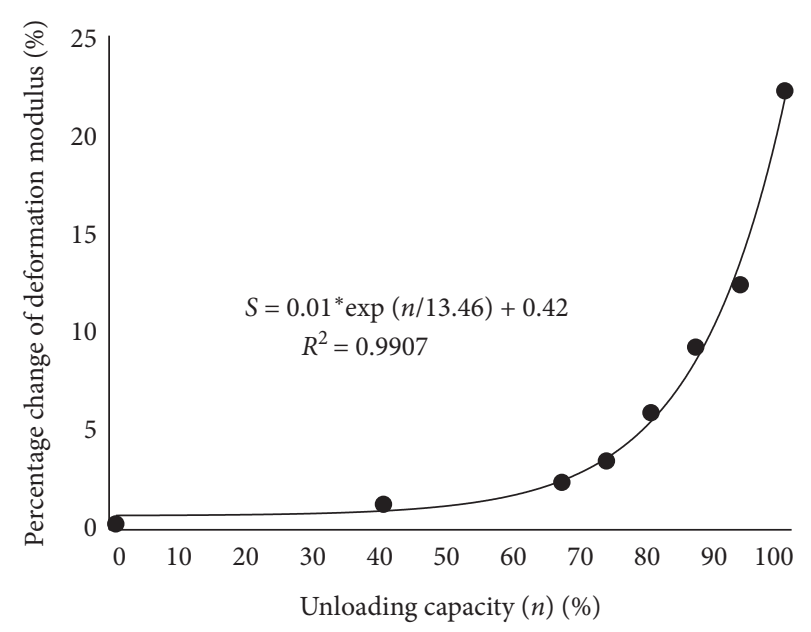

- Test results

_ Fitting curve

(b)

Figure 9: Change curves of the deformation modulus. (a) The curve of deformation modulus and unloading quantity at the unloading stage. (b) The curve between percentage change of deformation modulus and unloading quantity.

TABLE 2: Statistical table of the deformation modulus at the unloading stage.

\begin{tabular}{|c|c|c|c|c|c|c|c|c|c|}
\hline Confining pressure $(\mathrm{MPa})$ & Unloading capacity (\%) & $0.00 \%$ & $40.00 \%$ & $66.67 \%$ & $73.33 \%$ & $80.00 \%$ & $86.67 \%$ & $93.33 \%$ & $100 \%$ \\
\hline 12.5 & 100.00 & 21.47 & 20.97 & 20.58 & 20.36 & 19.90 & 19.54 & 18.89 & 16.71 \\
\hline 13.0 & 93.33 & 22.45 & 22.21 & 21.89 & 21.61 & 21.15 & 20.61 & 19.70 & - \\
\hline 13.5 & 86.67 & 23.17 & 22.72 & 22.27 & 22.07 & 21.85 & 21.07 & - & - \\
\hline 14.0 & 80.00 & 23.13 & 22.96 & 22.64 & 22.47 & 21.82 & - & - & - \\
\hline 14.5 & 73.33 & 22.99 & 22.80 & 22.54 & 22.25 & - & - & - & - \\
\hline 15.0 & 66.67 & 23.27 & 23.12 & 22.78 & - & - & - & - & - \\
\hline 17.0 & 40.00 & 22.77 & 22.54 & - & - & - & - & - & - \\
\hline
\end{tabular}

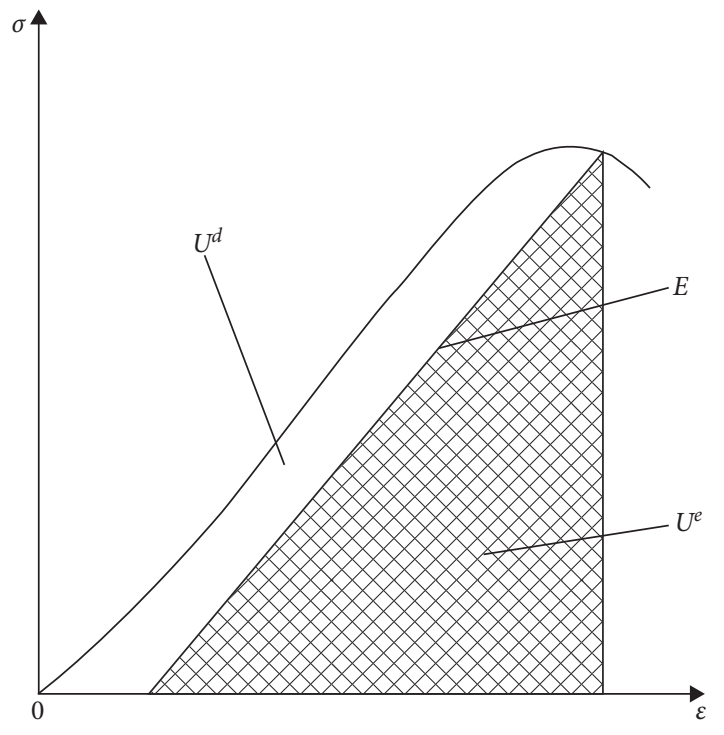

FIgURE 10: Stress-strain curve of rock.

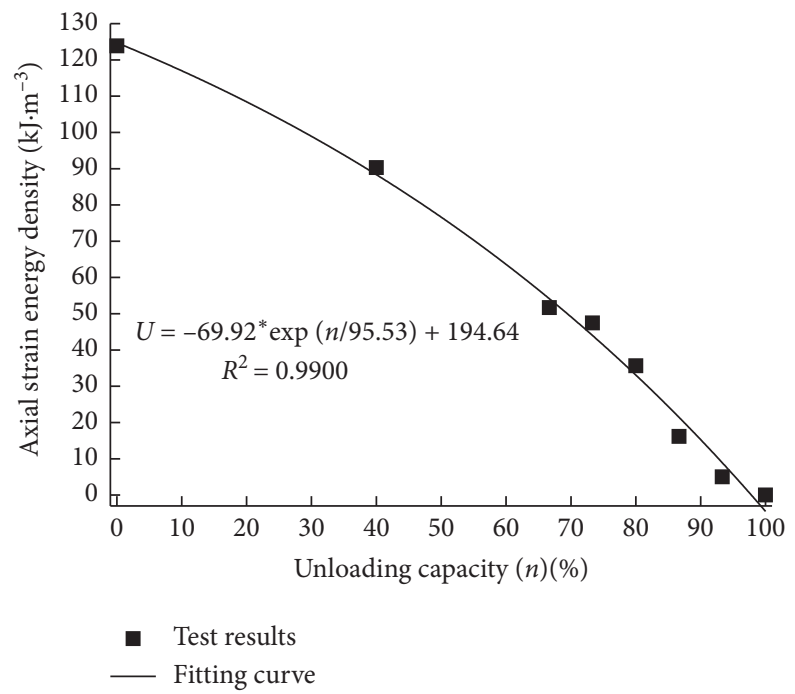

Figure 11: Relationship between axial strain energy density and unloading quantity. 


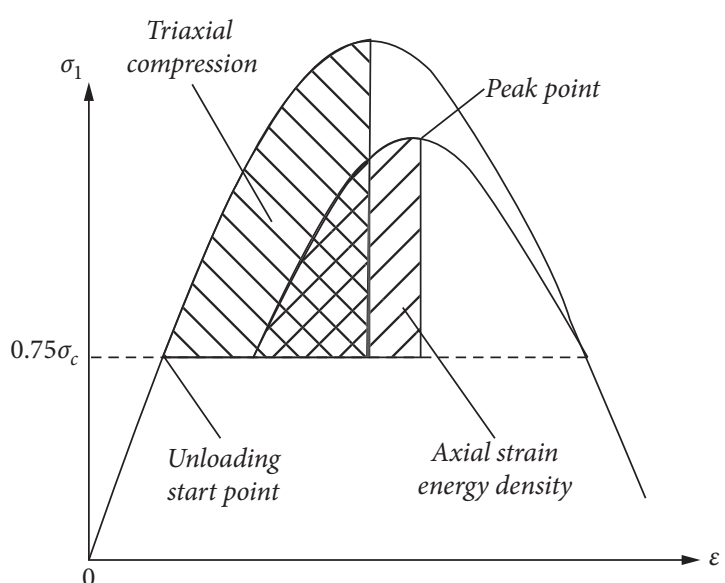

FIGURE 12: Schematic diagram of axial strain energy density.

energy density of adjacent unloading samples is recorded as the stage degradation degree $\Delta S_{i}$ [35]. And, we quantified it in the form of a percentage:

$$
\begin{gathered}
S_{i}=\frac{\left(U_{0}-U_{i}\right)}{U_{0}} \times 100 \%, \\
\Delta S_{i}=\frac{\left(U_{i}-U_{i-1}\right)}{U_{i}} \times 100 \%,
\end{gathered}
$$

where $U_{0}$ is the energy density when the unloading quantity is $0 \%$ and $U_{i}$ is the energy density of rock samples with different unloading quantities.

The variation curve of the total deterioration degree and stage deterioration degree of axial strain energy density is shown in Figure 13.

It can be seen from Figure 13 that

(1) In the unloading process, with the increase of unloading quantity, the total deterioration degree of the axial strain energy density of the rock sample increases gradually, and the degradation law is consistent, which shows a linear change first and then changes into a sudden rule. Moreover, when the unloading quantity is less than $80 \%$, the changing trend of the total deterioration degree of axial strain energy density is consistent with the peak strength law. After that, the deterioration trend of energy density suddenly increases. In comparison, with the increase of unloading quantity, the damage degree of the rock sample is higher and the changing trend of energy density is relatively obvious.

(2) During the unloading process, the nonuniformity of the deterioration degree of rock samples in the energy density stage is obvious. Under the condition of different unloading quantities, when the unloading quantity is less than $80 \%$, the stage deterioration degree of axial strain energy density is $35.0 \%$, which is obviously smaller. When the unloading quantity is greater than $80 \%$, the deterioration trend of the stage deterioration degree is obviously increased, which is $35.0 \%-100 \%$. Generally, the stage deterioration degree increases with the increase of unloading quantity, which indicates that the unloading damage effect of unloading quantity on the rock sample is gradually strengthened.

(3) Comparing the total degradation degree curve of energy density with that of the stage degradation degree, it can be seen that the change is linear or gentle when the unloading quantity is less than $80 \%$ and increases sharply when the unloading quantity is greater than $80 \%$. Also, the growth trend of the stage deterioration degree is more obvious. It shows that, with the increase of unloading quantity, especially when the unloading quantity is more than $80 \%$, the change rate of energy density is also gradually accelerated. When the unloading quantity is less than $80 \%$, the energy density loss is very small.

(4) It can be concluded that when $\Delta S<0.35$, there are no new cracks in the rock sample or the number of new cracks is small, so the damage degree of the rock sample is low. Therefore, the difference in peak strength between the unloading damage sample and the intact sample is small. The strain confining pressure compliance and deformation modulus tend to be stable. When $\Delta S \geq 0.35$, the deformation modulus and strain confining pressure compliance of the rock sample present the nonlinear mutation stage which has a steep slope. The results show that the peak strength of the specimen decreases sharply, and more new cracks are formed in the interior of the specimen during unloading, and the damage degree is large.

\subsubsection{Influence of Axial Strain Energy Density on Mechanical} Parameters. This section mainly discusses the correlation between axial strain energy density and mechanical parameters of sandstones during unloading. In this regard, the relationship between axial strain energy density and peak strength of sandstone specimens under different unloading quantities is given, as shown in Figure 14.

From Figure 14, it can be found that the axial strain energy density and peak strength present linear change. When the elastic strain energy stored in the sample is $0 \sim 120.45 \mathrm{~kJ} \cdot \mathrm{m}^{-3}$, the peak strength of the sample is 167.12 MPa 219.96 MPa. There is a positive correlation between them. This rule is reasonable because both of them are linearly related to the unloading quantity and have a sudden change at $80 \%$. In other words, before $80 \%$ of the unloading quantity, the internal crack development of the sample is not obvious and the sample can store more elastic energy. So the testing machine needs to do more work to destroy the sample; therefore, the peak strength is larger. When the unloading quantity exceeds $80 \%$, many through cracks are formed in the sample and the fracture development is complete. The elastic energy stored in the sample decreases sharply, and the specimen can be destroyed by the testing machine with only a small amount of work. The peak strength of the specimen will drop sharply. 


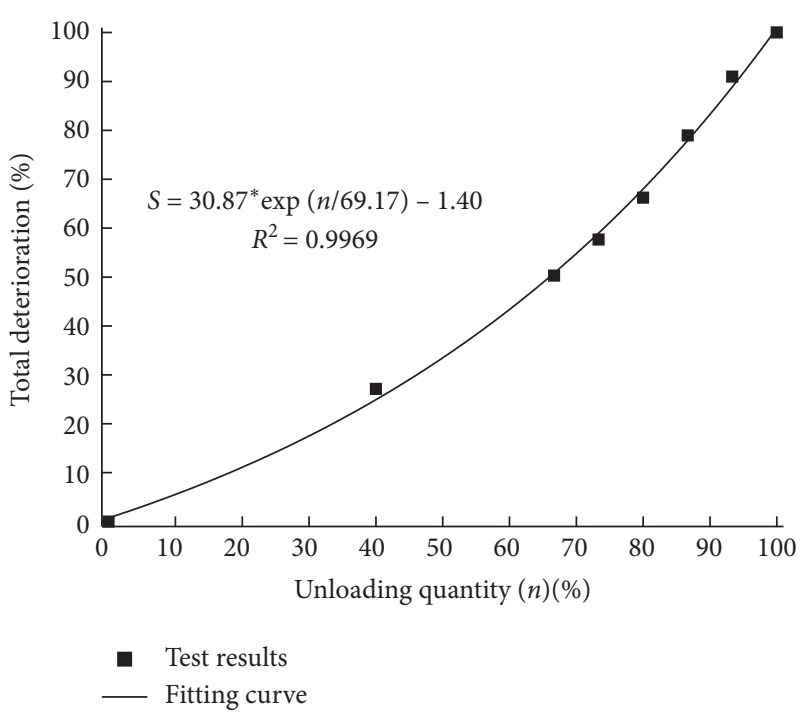

(a)

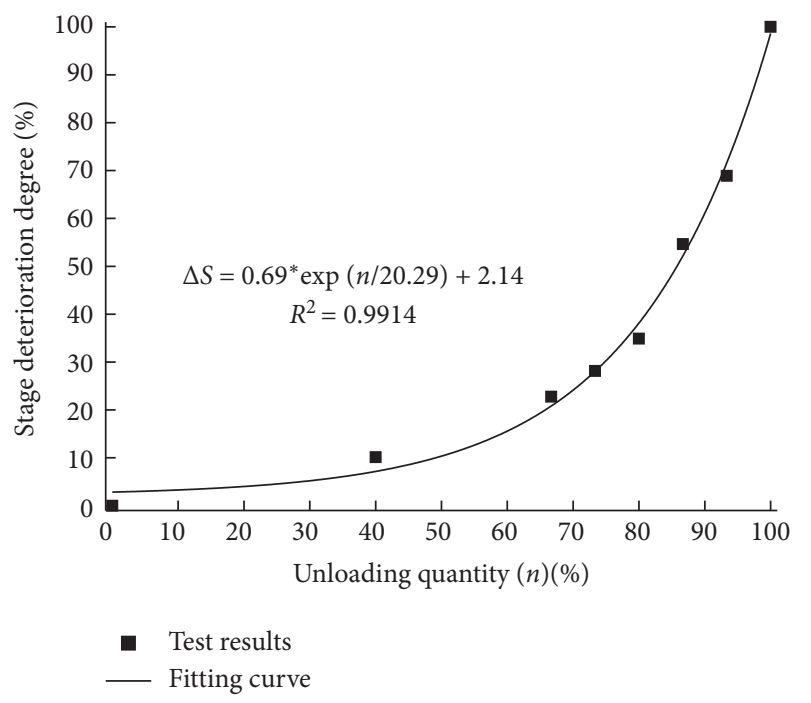

(b)

Figure 13: Axial strain energy density damage deterioration degree and unloading quantity. (a) Total deterioration degree of axial strain energy density and unloading quantity. (b) Stage deterioration degree and unloading quantity in the axial strain energy density stage.

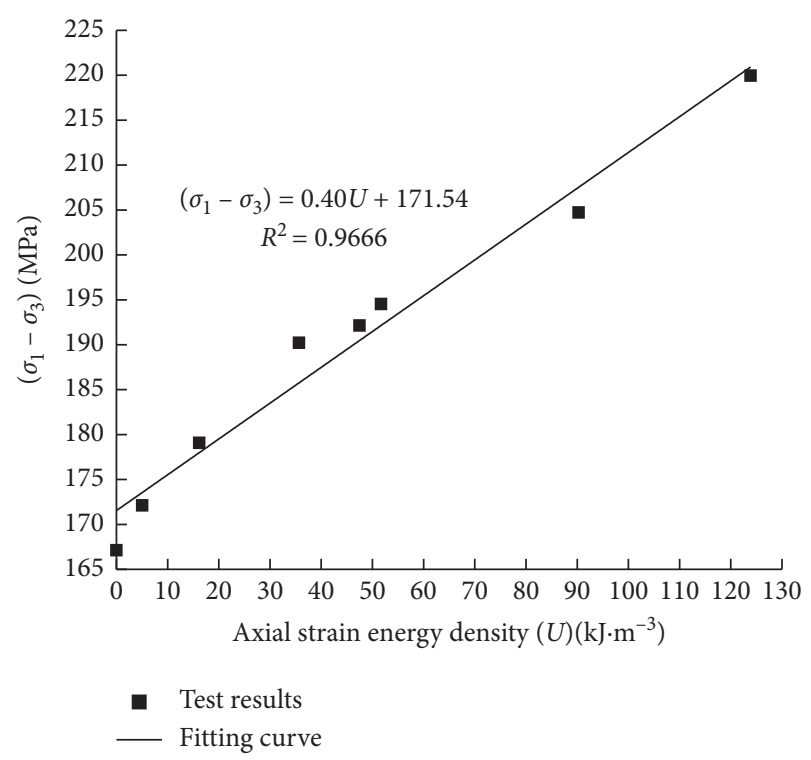

FIGURE 14: Relationship between axial strain energy density and peak strength.

3.6. Failure Mode of Rock Samples' Analysis. To further analyze the influence of unloading damage on the characteristics of sandstones, the failure mode of rock samples is analyzed. Due to space limitations, only typical photos of partial damage are listed. The failure diagram and fracture sketch of some typical rock samples in the conventional triaxial compression test are shown in Figure 15(a), and those of some typical rock samples with different initial unloading damage are shown in Figure 15(b).

From Figure 15, it can be seen that

(1) In the conventional triaxial compression test, the fracture mode of the specimen is a shear failure with only one fracture surface usually. In the unloading damaged rock sample, when the unloading quantity is small $(\Delta S<0.35)$, there is usually only one fracture surface. When the unloading quantity is large $(\Delta S \geq 0.35)$, a large number of secondary tensile cracks are produced.

(2) During the unloading process, there are many tensile microcracks in the rock sample. So, in the subsequent loading process, secondary tensile cracks are formed on both sides of the shear plane when the rock sample is damaged. When the unloading quantity is large $(\Delta S \geq 0.35)$, the specimen is more prone to fracture and the degree of failure is also relatively strong, and the tensile shear failure of the specimen mainly occurs. This point can also be seen in the test process, especially when the unloading quantity is large $(\Delta S \geq 0.35)$. The rock sample suddenly loses its strength, and the crisp fracture sound can be heard during the failure, which also indicates that the rock sample has a relatively strong brittle failure.

(3) The failure modes of rock samples with different unloading damage amounts are also different. When the unloading quantity is less than $80 \%(\Delta S<0.35)$, with the decrease of unloading quantity, the tensile crack at the end of the specimen gradually decreases, and the specimen changes from tensile shear failure to compression shear failure. The macroscopic failure surface is a single shear failure surface, and the failure mode is the same as that of a conventional triaxial compression test. When the unloading quantity is greater than $80 \%(\Delta S \geq 0.35)$, there are axial tensile fracture surfaces, secondary conjugate shear surface, primary conjugate shear surface, and tensile fracture surface producing. All kinds of tensile 


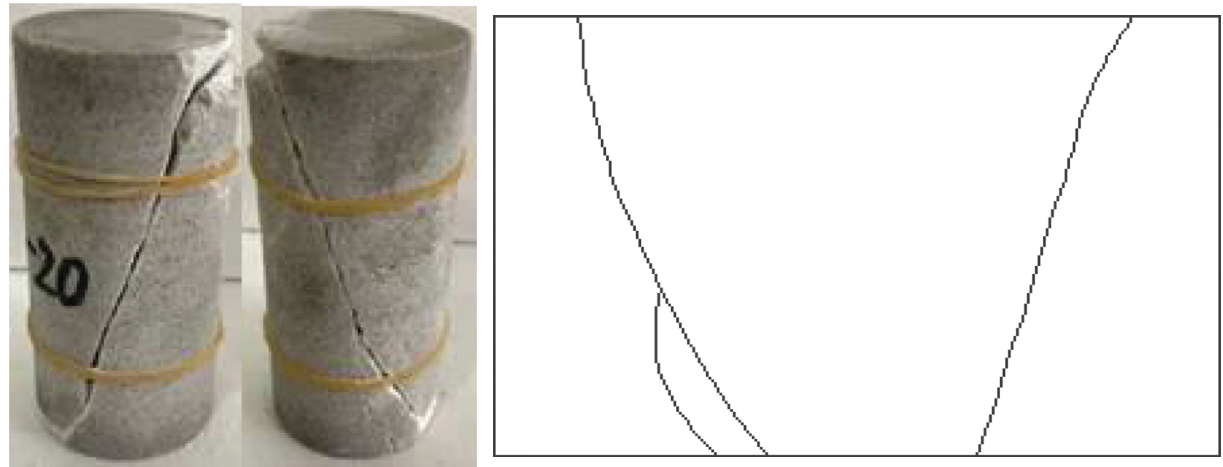

Confining pressure $12.5 \mathrm{MPa}$

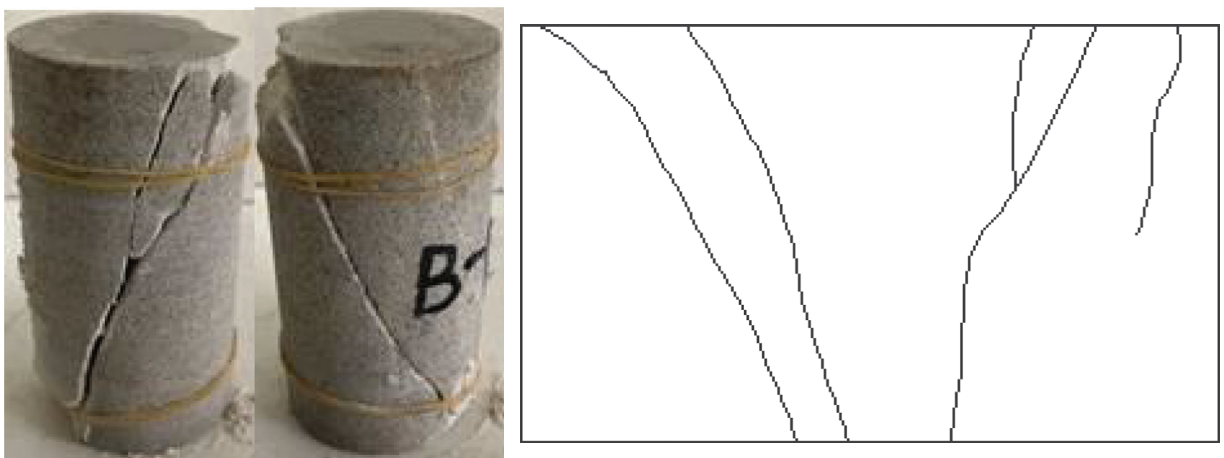

Confining pressure $20 \mathrm{MPa}$

(a)
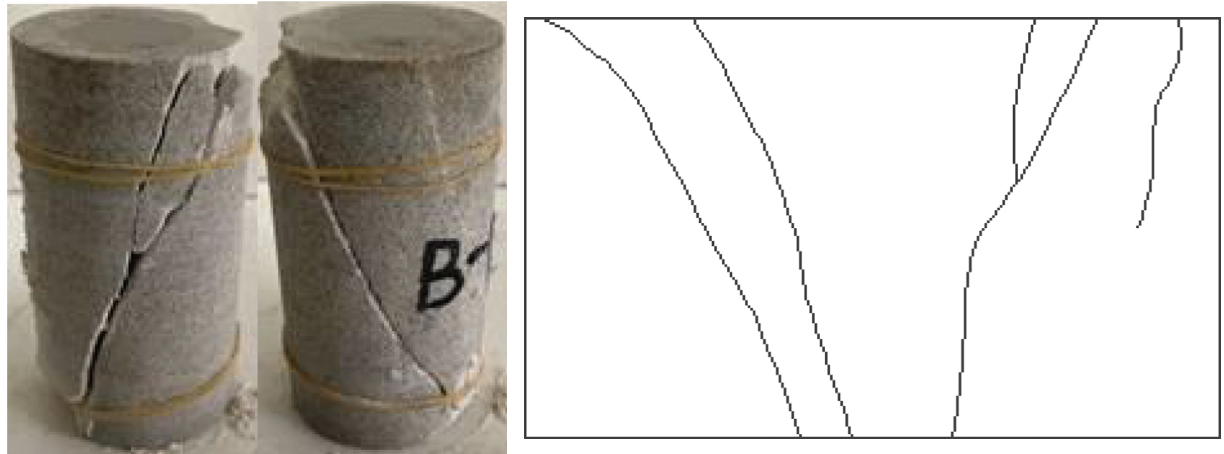

The unloading quantity is $0 \%$, the confining pressure at failure is $20 \mathrm{MPa}$
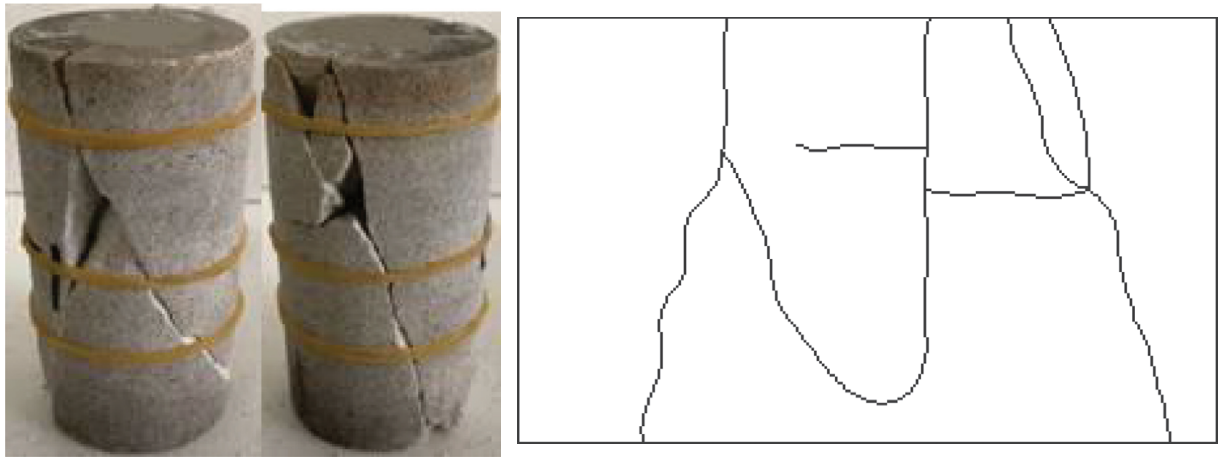

The unloading quantity is $100 \%$, the confining pressure at failure is $12.5 \mathrm{MPa}$

(b)

Figure 15: Failure diagram and crack diagram of a typical specimen. (a) Fracture diagram and fracture sketch of a typical rock sample in the conventional triaxial compression test. (b) Typical fracture diagram and fracture sketch of the unloading damaged rock sample. 
fractures are well developed, and the dilatancy along the unloading direction is obvious. The specimen shows tensile shear failure, and there are a certain number of axial cracks at the end of the specimen.

\section{Conclusions}

In this paper, triaxial compression tests are carried out on specimens with different initial unloading damage, and the results are compared with those of intact specimens. We come to the following conclusion:

(1) The influence of unloading quantity on the axial strain confining pressure compliance of rock samples is significant. There is a positive correlation between them, and the deformation is more obvious when the unloading quantity is more than $80 \%$.

(2) The unloading damage degradation factor $D$ is defined to analyze the unloading damage. When $D<0.4$, the strain confining pressure compliance and deformation modulus of the unloading damage sample tend to be stable, and the peak strength is not different from that of the intact sample. When $D \geq 0.4$, the deformation modulus and peak strength decrease rapidly, and the strain confining pressure compliance increases sharply.

(3) There is a positive linear correlation between the axial strain energy density and the peak strength. The greater the elastic energy stored, the higher the peak strength is.

(4) The failure mode is analyzed systematically from the angle of energy, and the degradation degree $\Delta S=0.35$ in the axial strain energy density stage is taken as the dividing line. When $\Delta S<0.35$, the specimen is mainly compression shear failure and the macroscopic failure surface is a single shear failure surface. When $\Delta S \geq 0.35$, the dilatancy characteristics of the specimen are obvious, which show tensile shear failure.

\section{Data Availability}

The test data are included within this article and can be made freely available.

\section{Conflicts of Interest}

The authors declare that there are no conflicts of interest regarding the publication of this paper.

\section{Acknowledgments}

This work was supported by the National Natural Science Foundation of China (nos. U1965109, 51809151, and 51679128) and sponsored by Research Fund for Excellent Dissertation of China Three Gorges University (no. 2020BSPY006).

\section{References}

[1] Z. Q. Yin and X. B. Li, "Research on damage and dynamic fragmentation characteristics of sandstone under unloading with confining pressers," China Safety Science Journal, vol. 23, no. 1, pp. 90-94, 2013.

[2] J. W. Gong, L. H. Wang, X. L. Xu et al., "Experimental study of unloading strength damage of sandstone based on HoekBrown failure criterion," Water Resources and Power, vol. 34, no. 4, pp. 100-102, 2016.

[3] J. J. Liu, W. J. Zhang, Q. H. Zhao et al., "Application of rock damage constitutive model in triaxial unloading test of marble," Subgrade Engineering, vol. 4, pp. 86-90, 2016.

[4] S. L. Qiu, X. T. Feng, C. Q. Zhang et al., "Experimental research on mechanical property of deep-buried marble under different initial damage levels and unloading paths," Chinese Journal of Rock Mechanics and Engineering, vol. 31, no. 8, pp. 1686-1697, 2012.

[5] L. Huo, Y. Zhou, C. H. Yang et al., "Experimental study of unloading mechanical behavior of mudstone in the different geological era," Rock and Soil Mechanics, vol. 38, no. 3, pp. 714-722, 2017.

[6] Q. S. Liu, K. D. Liu, X. L. Lu et al., "Study of mechanical properties of raw coal under high stress with triaxial unloading," Chinese Journal of Rock Mechanics and Engineering, vol. 33, no. 2, pp. 3429-3438, 2014.

[7] C. Liu, D. M. Zhang, D. L. Shang et al., "Influence of confining pressure unloading at post-peak on deformation and permeability characteristics of raw coal," Rock and Soil Mechanics, vol. 39, no. 6, pp. 2017-2024, 2018.

[8] J. L. Li, R. H. Wang, Y. Z. Jiang et al., "Experimental study of sandstone mechanical properties by unloading triaxial tests," Chinese Journal of Rock Mechanics and Engineering, vol. 29, no. 10, pp. 2034-2041, 2010.

[9] K. Wang, Y. R. Liu, C. Y. Niu et al., "Study on the unloading degradation and constitutive model of the rock," Science Technology and Engineering, vol. 15, no. 1, pp. 158-162, 2015.

[10] C. Apollaro, L. Marini, T. Critelli, and R. De Rosa, "The standard thermodynamic properties of vermiculites and prediction of their occurrence during water-rock interaction," Applied Geochemistry, vol. 35, pp. 264-278, 2013.

[11] M. Tallinn, B. Parisse, M. Petitta et al., "Long-term spatiotemporal hydrochemical and Rn-222 tracing to investigate groundwater flow and water-rock interaction in the Gran Sasso (central Italy) carbonate aquifer," Hydrogeology Journal, vol. 21, no. 7, pp. 1447-1467, 2013.

[12] P. Alt-Epping, L. W. Diamond, M. O. Häring, F. Ladner, and D. B. Meier, "Prediction of water-rock interaction and porosity evolution in a granitoid-hosted enhanced geothermal system, using constraints from the $5 \mathrm{~km}$ basel-1 well," Applied Geochemistry, vol. 38, pp. 121-133, 2013.

[13] Z. Hu, Y. R. Liu, P. Y. Wang et al., "USMR method for evaluating micro-mechanical parameters of slope rock mass deteriorated due to excavation unloading," Rock and Soil Mechanics, vol. 37, no. 12, pp. 3491-3498, 2016.

[14] Z. H. Zhong, X. H. Li, J. Z. Lu et al., "Anchorage behavior of specimens containing a single fissure based on digital image correlation and numerical method," Chinese Journal of Geotechnical Engineering, vol. 39, no. 7, pp. 1225-1233, 2017.

[15] W. D. Ni and Y. Xu, "Excavation characteristic analysis of columnar jointed rock mass considering unloading damage," Yangtze River, vol. 48, no. 1, pp. 69-74, 2017.

[16] L. Liu, H. B. Jia, and S. Z. Ma, "A fracture damage model for rock slopes under unloading and its application," Chinese 
Journal of Rock Mechanics and Engineering, vol. 34, no. 4, pp. 747-754, 2015.

[17] Z. H. Zhu, L. Y. Wei, Q. B. Meng et al., "Energy evolution characteristics of unloading failure of coal samples under different unloading confining pressure rates," Chinese Journal of Rock Mechanics and Engineering, vol. 38, no. 4, pp. 747756, 2019.

[18] D. P. Ma, Y. Zhou, C. X. Liu et al., "Energy evolution characteristics of unloading failure of coal samples under different unloading confining pressure rates," Rock and Soil Mechanics, vol. 40, no. 7, pp. 2645-2652, 2019.

[19] J. L. Li, Z. H. Zhu, L. Y. Wei et al., "Damage characterization and energy dissipation characteristics of marble under unloading before peak load," Chinese Journal of Rock Mechanics and Engineering, vol. 39, no. 12, pp. 2429-2438, 2020.

[20] C. B. Jiang, C. Wei, W. J. Zhuang et al., "Deformation characteristics and energy evolution mechanism of shale under constant amplitude cyclic loading," Chinese Journal of Rock Mechanics and Engineering, vol. 39, no. 12, pp. 24162428, 2020.

[21] J. Zhao, G. T. Guo, and D. P. Xu, "Experimental study on deformation and failure characteristics of deep-buried hard rock under triaxial and cyclic loading and unloading stress paths," Rock and Soil Mechanics, vol. 41, no. 5, pp. 1521-1530, 2020.

[22] L. Q. Chen, J. S. Zhang, J. H. Chen et al., "Influences of initial damage on mechanics of brittle rock under compressed stress," Journal of Central South University (Science and Technology), vol. 48, no. 2, pp. 484-490, 2017.

[23] Y. Luo, X. P. Li, Q. Dong et al., "Damage cause study for static and dynamic combination of excavation and unloading in deep underground tunnels," Chinese Journal of Rock Mechanics and Engineering, vol. 34, no. 1, pp. 3365-3371, 2015.

[24] K. G. Li, B. W. Yang, Q. C. Qin et al., "Experimental study on unloading damage and permeability characteristics of dolomite based on nuclear magnetic resonance technology," Chinese Journal of Rock Mechanics and Engineering, vol. 38, no. 2, pp. 3493-3502, 2019.

[25] Y. Wang, Q. Ai, J. L. Li et al., "Study on damage characteristics and unloading failure meso characteristics of sandstone considering different influence factors," Rock and Soil Mechanics, vol. 40, no. 4, pp. 1341-1350, 2019.

[26] B. Dai, G.-y. Zhao, H. Konietzky, and P. L. P. Wasantha, "Experimental investigation on damage evolution behaviour of a granitic rock under loading and unloading," Journal of Central South University, vol. 25, no. 5, pp. 1213-1225, 2018.

[27] S.-L. Qiu, X.-T. Feng, J.-Q. Xiao, and C.-Q. Zhang, “An experimental study on the pre-peak unloading damage evolution of marble," Rock Mechanics and Rock Engineering, vol. 47, no. 2, pp. 401-419, 2014.

[28] Z. Zhang, X. Yu, and M. Deng, "Damage evolution of sandy mudstone mechanical properties under mining unloading conditions in gob-side entry retaining," Geotechnical and Geological Engineering, vol. 37, no. 4, pp. 3535-3545, 2019.

[29] C. Wang, J. Xu, X. Zhao, and M. Wei, "Fractal characteristics and its application in electromagnetic radiation signals during fracturing of coal or rock," International Journal of Mining Science and Technology, vol. 22, no. 2, pp. 255-258, 2012.

[30] J. Yu, W. Yao, K. Duan, X. Liu, and Y. Zhu, "Experimental study and discrete element method modeling of compression and permeability behaviors of weakly anisotropic sandstones," International Journal of Rock Mechanics and Mining Sciences, vol. 134, Article ID 104437, 2020.
[31] C. Yang, Z. X. Hu, and D. Huang, "Failure mechanism of primary support for a shallow and asymmetrically loaded tunnel portal and treatment measures," Journal of Performance of Constructed Facilities, vol. 34, no. 1, Article ID 04019105, 2020.

[32] H. F. Deng, H. B. Zhang, J. L. Li et al., "Effect of water-rock interaction on unloading mechanical properties and microstructure of sandstone," Rock and Soil Mechanics, vol. 39, no. 7, pp. 2344-2352, 2018.

[33] H. F. Deng, Z. Wang, J. L. Li et al., "Effect of unloading rate and pore water pressure on mechanical properties of sandstone," Chinese Journal of Geotechnical Engineering, vol. 39, no. 11, pp. 1976-1983, 2017.

[34] W. Z. Chen, S. P. Lv, X. H. Guo et al., "Research on unloading confining pressure tests and rockburst criterion based on energy theory," Chinese Journal of Rock Mechanics and Engineering, vol. 28, no. 8, pp. 1530-1540, 2009.

[35] Y. Fu, X. R. Liu, Y. X. Zhang et al., "Study of the influence of water-rock interaction to the strength of sandstone," Hydrogeology \& Engineering Geology, vol. 36, no. 6, pp. 54-58, 2009. 